Институт систел энергетики ил. Л. А. Мелентьева Сибирского отделения Российской акаделии наук 2. Иркутск, Российская Федерация Е. А. Локтионова Байкальский государственный университет, г. Иркутск, Российская Федерация

\title{
ОЦЕНКА ВЛИЯНИЯ ПАДЕНИЯ ЦЕН НА НЕФТЬ И УХУДШЕНИЯ ОБЩЕЭКОНОМИЧЕСКОГО СОСТОЯНИЯ СТРАНЫ НА ФИНАНСОВУЮ ПРИВЛЕКАТЕЛЬНОСТЬ ИНВЕСТИЦИЙ В АКЦИИ ЭНЕРГЕТИЧЕСКИХ КОМПАНИЙ
}

\begin{abstract}
АннотАция. Анализ ситуации, сложившейся на отечественном фондовом рынке, а также в экономике и энергетике, показал, что резкое падение цен на нефть на мировом энергетическом рынке в 2014 году незначительно снизило инвестиционную привлекательность вложений в акции отечественных энергетических компаний. В настоящее время риски и неопределенность будущего развития политических и экономических событий снижают инвестиционную привлекательность финансовых вложений в акции российских энергетических компаний значительно сильнее, чем падение цен на нефть. Рассмотрев различные фундаментальные факторы, влияющие на динамику курса акций энергетических компаний России, был сделан вывод о том, что в среднесрочной и долгосрочной перспективе падение курса акций российских энергетических компаний не ожидается. Энергетические компании, таким образом, в среднесрочной перспективе могут рассчитывать на привлечение средств отечественного фондового рынка для решения стоящих перед ними текущих и стратегических задач обеспечения надежных поставок энергетических ресурсов потребителям, поддерживая тем самым адаптивность энергетических систем России на необходимом уровне.

кЛЮЧЕВЫЕ СЛОВА. Инвестиции; кризис; энергетика; акции; нефть.

ИНФОРМАЦИЯ О СТАТЬЕ. Дата поступления 21 января 2018 г.; дата принятия к печати 19 марта 2018 г.; дата онлайн-размещения 09 апреля 2018 г.

ФИНАНСИРОВАНИЕ. Работа выполнена при финансовой поддержке гранта РФФИ № 17-06-00102-a.
\end{abstract}

V. I. Loktionov

Melentiev Energy Systems Institute, Siberian Branch of the Russian Academy of Sciences Irkutsk, Russian Federation

E. A. Loktionova Baikal State University, Irkutsk, Russian Federation

\section{ASSESSMENT OF IMPACT OF THE SHARP PRICE DROP OF CRUDE OIL AND ECONOMIC CRISIS ON ATTRACTIVENESS OF STOCK INVESTMENT IN POWER COMPANIES}

\begin{abstract}
Analysis of the situation on the domestic stock market, as well as in the economy and power economy, showed that a sharp drop in oil prices in the world energy market in 2014 has slightly reduced the investment attractiveness of investments in the shares of domestic energy companies. Nowadays, the risks and uncertainty of the future development of the political and the economic events reduce the investment attractiveness of financial investments in the shares of Russian energy companies much stronger than the fall in oil prices. The article considers the
\end{abstract}

(C) В. И. Локтионов, Е. А. Локтионова, 2018

\section{Baikal Research Journal}


various fundamental factors influencing the dynamics of share price of the energy companies in Russia and concludes that the decline in share price of the Russian energy companies is not expected in mid-term and long term periods. Therefore, the energy companies can rely on raising the funds of the domestic stock market in the mid-term period for solving the current and strategic challenges that they face to ensure a reliable supply of the energy resources to consumers, thereby supporting the adaptability of the Russia's energy systems at the required level.

KEYWORDS. Investment; crisis; power engineering; stocks; oil.

ARTICLE INFO. Received January 21, 2018; accepted March 19, 2018; available online April 09, 2018.

ACKNOWLEDGEMENTS. The article was prepared with the financial support of Russian Foundation for Basic Research (RFBR) (grant № 17-06-00102-A).

В 2014 г. реализовалась угроза, о которой давно предупреждали многие специалисты: высокая зависимость экономики России от валютных поступлений, связанных с экспортом нефти и газа, привела к тому, что быстрое падение мировых цен на углеводороды вызвало резкое снижение доходов как отдельных энергетических компаний, так и государства в целом, а экономика России столкнулась с очередными кризисными явлениями.

На протяжении большей части последнего десятилетия, цены на нефть были высокими (рис. 1), что обуславливалось рядом таких факторов, как рост потребления нефти Китаем (с 224,2 млн т. в 2000 г. до 578,7 млн т. в 2016 г.) на фоне роста мирового потребления первичных энергоресурсов (с 9371,3 млн тон нефтяного эквивалента (т.н.э.) в 2000 г. до 13 276,3 млн т.н.э. в 2016 г.), а также военными конфликтами в странах Ближнего Востока. В результате рост мировой добычи нефти за период с 2001 г. по 2013 г. (с 3617,5 млн т. до 4126,6 млн т.) не покрывал роста спроса на нефть, что сопровождалось ростом цен, претерпевшими снижение только в период мирового кризиса 2008-2009 гг. ${ }^{1}$

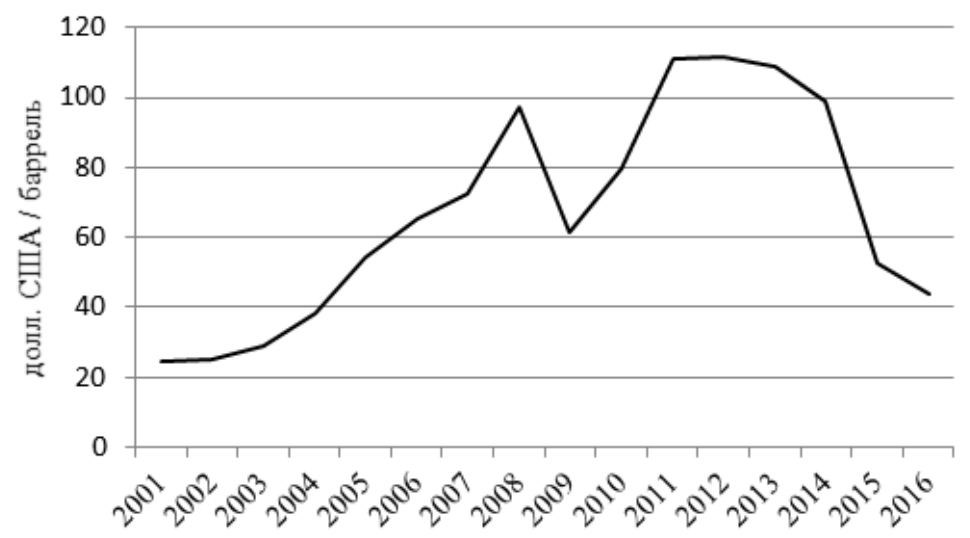

Рис. 1. Диналика иены на нефть марки Brent в 2001-2016 22.

На фоне высоких мировых цен на нефть Россия, обладая значительными запасами первичных энергетических ресурсов, а также производственными мощностями по их добыче, переработке и транспортировке, утвердилась в статусе одного из мировых лидеров на рынке первичных энергетических ресурсов [1].

${ }^{1}$ Statistical Review of World Energy 2017. URL: https://www.bp.com/en/global/corporate/energyeconomics/statistical-review-of-world-energy/downloads.html.

\section{Baikal Research Journal}


Высокие цены на нефть стимулировали в США и Канаде инвестиционные вложения в развитие нефтедобычи в труднодоступных сланцевых пластах Северной Дакоты (США) и нефтеносных песках в провинции Альберта (Канада). В 2014 г. темп роста спроса на нефть в Европе, Азии и США стал замедляться благодаря снижению темпов мирового экономического роста, развитию «зеленой» энергетики и повышению энергоэффективности производства в развитых странах. К концу 2014 г. мировая добыча нефти заметно превышала спрос на нее, что привело к резкому падению цен. Если в июне 2014 г. цена на сырую нефть марки Brent coставляла порядка 111 долл. за баррель, то в январе 2015 г. она упала до 48 долл. за баррель [2].

Падение цен на нефть на мировом рынке сопровождалось падением реального ВВП России (рис. 2). Реальный ВВП России за период с 2014 г. по 2016 г. упал на $2,7 \%$, при этом номинальный ВВП вырос на 8,5 \% ${ }^{2}$. Следует отметить, что снижение реального ВВП было связано не с сокращением добычи нефти и газа, а со спадом производства в других отраслях реального сектора экономики: добыча нефти увеличилась в 2016 г. по сравнению с 2014 г. на 4 \% и составила 547,3 млн т. Объем экспорта нефти увеличился с 221,53 млн т. в 2014 году до 253,67 млн т. в 2016 г.

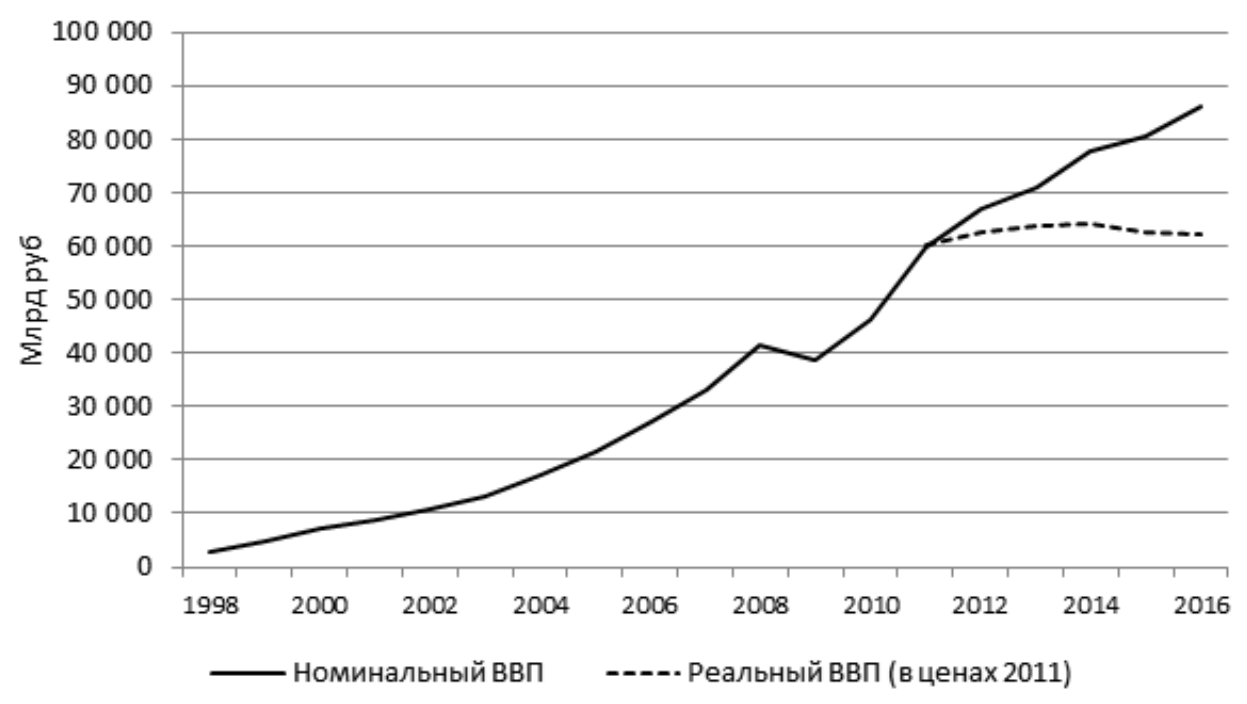

Рис. 2. Динамика реального и номинального ВВП в 2011-2016 г2.

В сложившейся ситуации стратегической целью отечественных энергетических компаний является их выход на траекторию постоянного и устойчивого развития с минимальными экономическими потерями, чему могут способствовать как прямые, так и финансовые инвестиции.

По данным Росстата, кризисные явления в экономике России в 2014-2015 гг. не привели к снижению прямых инвестиций в основной капитал добывающих энергетических компаний (рис. 3$)^{3}$.

\footnotetext{
${ }^{2}$ Национальные счета. Информация о пересмотре динамического ряда. URL: http://www.gks.ru/ wps/wcm/connect/rosstat_main/rosstat/ru/statistics/accounts/\#.

3 Инвестиции в основной капитал. URL: http://www.gks.ru/wps/wcm/connect/rosstat_main/ rosstat/ru/statistics/enterprise/investment/nonfinancial/\#.
}

\section{Baikal Research Journal}




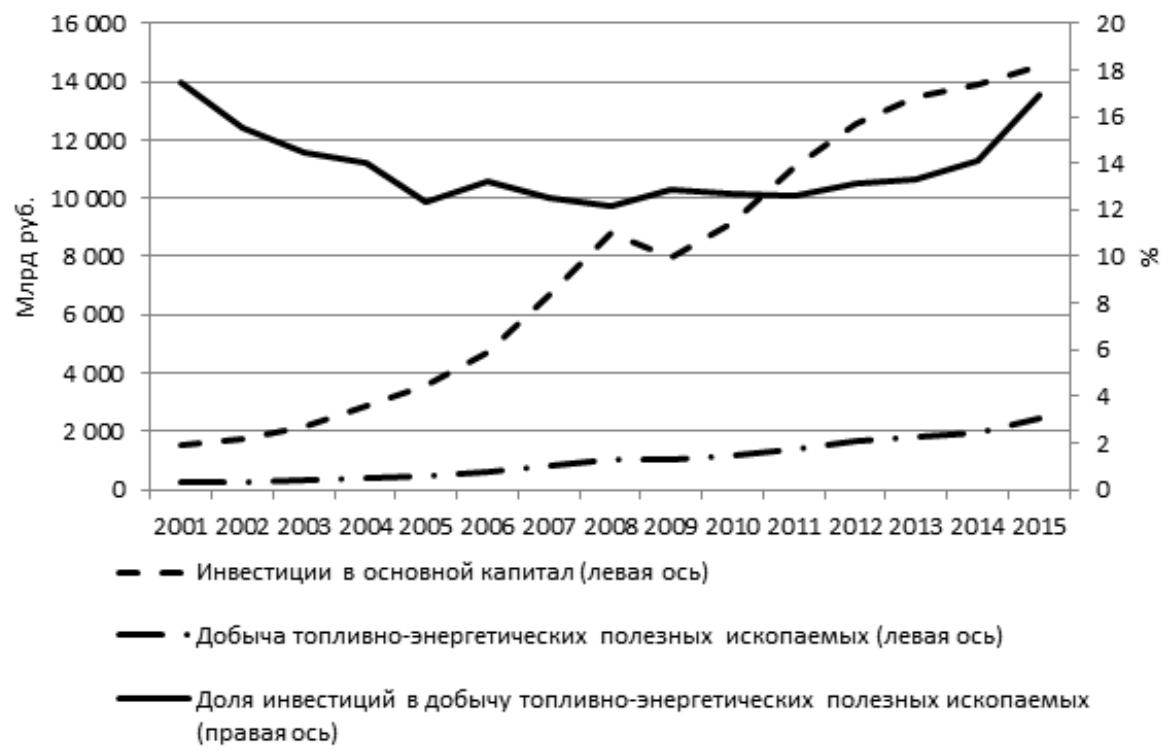

Рис. 3. Динамика инвестиций в основной капитал в 2001-2015 г2.

По прогнозу Минэкономразвития, в 2018 г. объем инвестиций в основной капитал топливно-энергетического комплекса останется на уровне 2017 г., снизившись на $1,4 \%$ по сравнению с уровнем 2016 г. К 2020 г. ожидается рост инвестиций в добычу топливно-энергетических полезных ископаемых на $2,1 \%{ }^{4}$. Учитывая тот факт, что по итогам первого полугодия размер капитальных вложений в российскую экономику в целом составил 4,8 \% от уровня ВВП, можно сделать вывод о крайней недостаточности осуществляемых прямых инвестиций для әффективного развития ТЭК России.

В отношении финансовых инвестиций можно отметить следующее. Фондовый рынок является чутким индикатором, отражающим влияние меняющихся социально-экономических и политических условий на деятельность компаний. В то же время на фондовом рынке под действием множества разнообразных и разнородных факторов формируются среднесрочные и долгосрочные тренды изменения курса акций, определяющие тем самым текущее экономическое положение отдельных компаний и экономики страны в целом, а на краткосрочные тенденции сильное влияние оказывают спекулятивные сделки и панические настроения инвесторов.

По данным Группы «Московская Биржа», по итогам первого полугодия 2017 г. семь из десяти наиболее капитализированных российских компаний относятся к нефтегазовому сектору экономики, а их доля в общей капитализации российского рынка акций составляет $41,4 \%$ (табл.).

Наиболее капитализированные компании российского рынка акций

\begin{tabular}{|c|l|r|r|}
\hline \multirow{2}{*}{$№$} & Эмитент & Капитализация, млрд дол. & $\begin{array}{r}\text { Доля в общей капитализации } \\
\text { рынка, \% }\end{array}$ \\
\hline 1 & ОАО «НК «Роснефть» & 58,8 & 10,6 \\
\hline 2 & ПАО «Сбербанк России» & 55,2 & 9,9 \\
\hline
\end{tabular}

${ }^{4}$ Прогноз социально-экономического развития Российской Федерации на 2018 год и на плановый период 2019 и 2020 годов. URL: http://economy.gov.ru/minec/about/structure/depmacro/2017271001.

\section{Baikal Research Journal}


Окончание табл.

\begin{tabular}{|c|l|r|r|}
\hline \multirow{2}{*}{$№$} & \multicolumn{1}{|c|}{ Эмитент } & Капитализация, млрд дол. & $\begin{array}{c}\text { Доля в общей капитализации } \\
\text { рынка, \% }\end{array}$ \\
\hline 3 & ОАО «ГАЗПРОМ» & 47,8 & 8,6 \\
\hline 4 & ОАО «НК «ЛУКОЙЛ» & 41,6 & 7,5 \\
\hline 5 & ОАО «НОВАТЭК» & 33,3 & 6,0 \\
\hline 6 & $\begin{array}{l}\text { ОАО «ГМК «Норильский } \\
\text { никель» }\end{array}$ & 21,9 & 3,9 \\
\hline 7 & ОАО «Сургутнефтегаз» & 19,3 & 3,5 \\
\hline 8 & ОАО «Газпром нефть» & 14,7 & 2,6 \\
\hline 9 & $\begin{array}{l}\text { ОАО «Татнефть» } \\
\text { им. В.Д. Шашина }\end{array}$ & 14,6 & 2,6 \\
\hline 10 & ПАО «Магнит» & 14,5 & 2,6 \\
\hline
\end{tabular}

Источник: составлено автором на основе обзора НАУФОР 5

В связи с этим, негативные тенденции в ценовой динамике их акций могут отрицательно повлиять на состояние российского фондового рынка в целом. Учитывая то, что фондовый рынок является одним из наиболее эффективных источников финансирования современной экономики, данное обстоятельство усиливает чрезмерную зависимость экономики России от доходов энергетического сектора. Следует отметить, что цены на энергоносители и общее состояние мировых энергетических рынков оказывают влияние не только на отечественный фондовый рынок, но и на мировые. Эта связь хорошо отражена в публикациях таких авторов, как Алоуиа Р. [3], Баруник Дж. [4], Щолтенс Б. [5], Во М. [6]. Оценка последствий финансово-экономического кризиса для фондового рынка также является актуальной темой исследований, которой посвящены работы Црнигой М. [7], Димица Н. [8], Горяева А. [9], Граута П. А. [10], Ли Дж. [11], Чены Ф. [12], Абрамова А. [13], Минтона Б. А. [14], Райта Г. [15] и др.

В процессе оценки изменения инвестиционной привлекательности финансовых вложений в акции российских энергетических компаний необходимо учитывать следующее. Прогнозирование цен на энергоносители, их влияния на экономику, динамику фондового рынка и курса акций отдельных компаний, является сложной задачей. Как показано в исследованиях Кононова Ю. Д. [16], Гальперовой Е. В. [17], Локтионова В. И. [18; 19], Кибалова Е. Б. [20], взаимосвязи между экономикой, энергетическими рынками и ценами на энергоносители часто имеют недетерминированный характер. Поэтому оценивать влияние падения цен на энергоносители на инвестиционную привлекательность финансовых вложений в акции отечественных энергетических компаний необходимо, опираясь на анализ динамики фондового рынка с помощью инструментов фундаментального и технического анализа, в контексте существующих экономических тенденций и взаимосвязей экономики и энергетики.

Рыночная стоимость компании представляет собой приведенную стоимость ожидаемых будущих денежных потоков. Рост цен на нефть влияет на будущие денежные потоки компании либо отрицательно, либо положительно в зависимости от того, является ли она производителем или потребителем нефти и нефтепродуктов. Ценовая динамика акций компаний, являющихся производителями нефти и нефтепродуктов, преимущественно отражается отраслевым индексом «Нефть и газ» Московской Биржи, а ценовая динамика акций энергетических компаний,

${ }^{5}$ Российский фондовый рынок. События и факты. Обзор за первое полугодие 2017 года. URL: http://www.naufor.ru/tree.asp?n=4333.

\section{Baikal Research Journal}


являющихся потребителями нефти и нефтепродуктов - отраслевым индексом «Электроэнергетика» Московской Биржи.

Анализируя динамику отраслевого индекса «Нефть и газ» (рис. 4), можно заметить, что курсы акций энергетических компаний существенно потеряли в своей стоимости в течение мирового финансово-экономического кризиса 2007-2008 гг., который сопровождался значительным падением цен на нефть и газ.

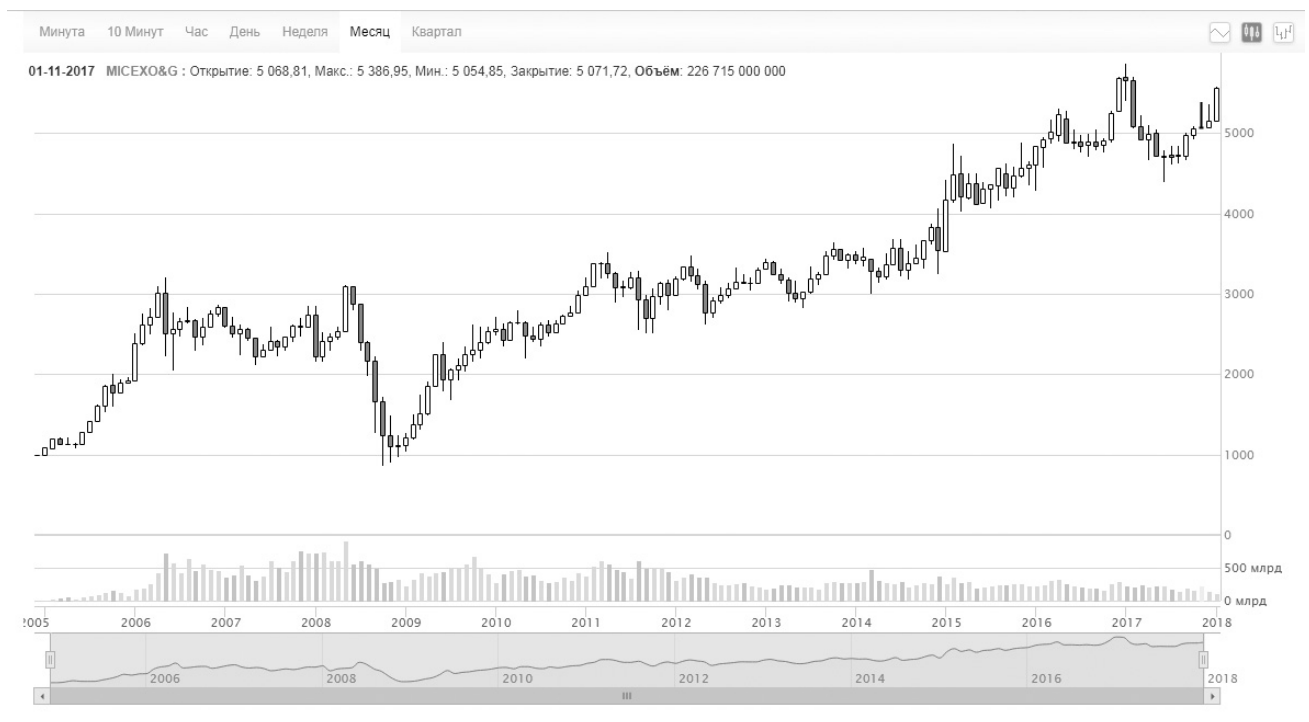

Рис. 4. Диналика индекса «Нефть и газ» Московской биржи за 2005-2018 г2.

В этот период акции многих энергетических компаний подешевели в разы. Так, например, курс акций ОАО «НК «Роснефть» в 2008 г. снизился с 286 руб. до 108,5 руб., а курс акций ОАО «ГАЗПРОМ» упал с 360 руб. до 108 руб.

С 2009 г. по 2018 г. значение отраслевого индекса нефтегазового сектора выросло с 1120 п. до 5567 п. На рис. 4 видно, что рост не был стабильным. В период с 2009 г. по 2011 г. произошло восстановление курса акций большинства нефтяных компаний. Например, курс акций ОАО «НК «Лукойл», достигнув минимальной отметки в 880 руб., начиная с конца 2008 г. стал стабильно расти и в январе 2018 г. составил 3840 руб. Акции ОАО «НК «Роснефть» также стабильно росли в течение рассматриваемого периода, достигнув уровня в 350 руб. в марте 2017 г. В то же время курс акций ОАО «ГАЗПРОМ» после падения в 2008 г. не смог отыграть своего докризисного значения в 360 руб. и колеблется в районе 150 руб. $^{6}$

В 2011-2013 гг., составив конкуренцию российским компаниям, на мировые энергетические рынки вышли производители сланцевой нефти и газа США, а начавшийся рост рынка СПГ привел к тому, что европейские страны в целях обеспечения собственной энергетической безопасности стали диверсифицировать структуру поставщиков энергоресурсов. Нестабильность положения России на мировом энергетическом рынке в этот период, в частности, проявлялась в том, что значение отраслевого индекса «Нефть и газ» находилось в ценовом коридоре, ограниченном уровнями 2500 п. и 3500 п. Ситуация резко изменилась в 2014 г.: осложнение политической обстановки в мире, последовавшие экономиче-

${ }^{6}$ Итоги торгов. URL: http://www.moex.com/ru/marketdata/\#/group=4\&collection=3\&boardgroup $=57 \&$ data_type $=$ history $\&$ mode $=$ groups $\&$ sort $=$ VALUE\&order $=$ desc $\&$ date $=2018-01-18$

\section{Baikal Research Journal}


ские и политические санкции против России, а также начавшееся снижение цен на нефть привели к ухудшению общей экономической ситуации в стране и обвалу национальной валюты.

Снижение курса национальной валюты обычно выгодно экспортерам, так как они получают дополнительные доходы от обмена полученной иностранной валюты на национальную валюту. Несмотря на то, что существенную часть доходов федерального бюджета России составляют валютные поступления от экспорта нефти и газа, экономику России нельзя назвать экспортоориентированной в чистом виде, поскольку в связи с устойчивым дефицитом инвестиций в развитие российской промышленности в структуре потребления значительно увеличилась доля импортируемого оборудования, транспорта и продукции химического производства. Таким образом, экономика России в целом сильно проиграла от снижения курса рубля по отношению к доллару, а отдельные нефтяные компании, напротив, выиграли. Укрепление доллара компенсировало их убытки от падения мировых цен на нефть, что способствовало перетеканию средств инвесторов из других секторов экономики в нефтегазовую отрасль и росту курса акций нефтедобывающих и нефтеперерабатывающих компаний. Очевидно, что в текущей ситуации риски и неопределенность будущего развития политических и экономических событий снижают инвестиционную привлекательность финансовых вложений в акции отечественных энергетических компаний значительно сильнее, чем падение цен на нефть.

Однако энергетический сектор России включает в себя не только компании, занимающиеся добычей и транспортировкой энергетических ресурсов, но и компании, производящие электроэнергию. Не имея отношения к экспорту первичных энергетических ресурсов, а являясь их потребителями (ТЭЦ и ТЭС), они, как и большинство российских компаний, ощутили на себе последствия кризисных явлений в экономике. Завершившееся к 2011 г. реформирование российского рынка электроэнергии, вызванное необходимостью его либерализации, вкупе с несовершенством существовавшей системы ценообразования на рынке электроэнергии привели к ухудшению экономического состояния ряда компаний электроэнергетического сектора, что повлекло за собой падение курса их акций (рис. 5).

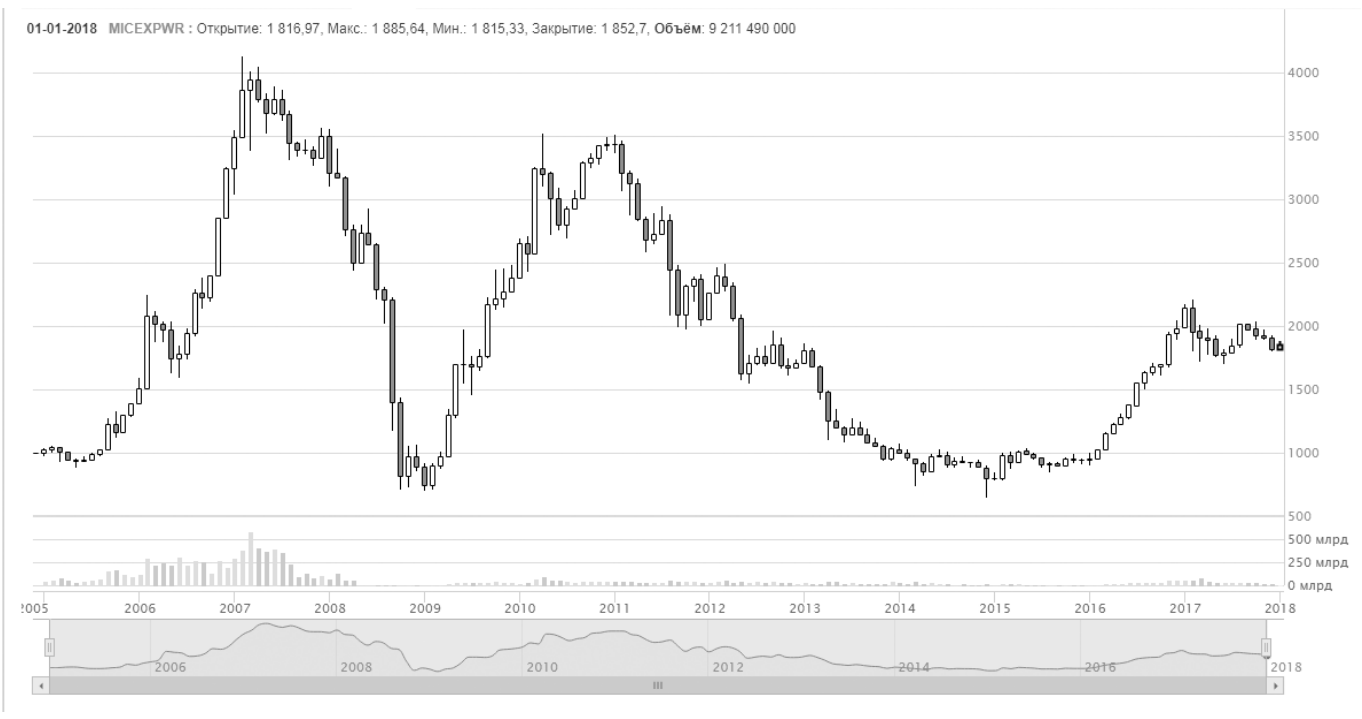

Рис. 5. Диналика индекса «Электроэнергетика» Московской биржи за 2005-2018 г2.

\section{Baikal Research Journal}


Положительная динамика на рынке акций электроэнергетических компаний началась только в 2016 г., однако ввиду низкого интереса отечественных инвесторов к данному сегменту российского фондового рынка потенциал роста курса акций электроэнергетических компаний до сих пор не реализован.

Инвестиционная привлекательность вложений в акции энергетических компаний, а вместе с ней и курс акций, определяется не только ценами на энергоносители, но и рисками, связанными с данными вложениями. Источниками основных рисков инвестирования в акции энергетических компаний в настоящее время выступают высокая волатильность цен на энергоресурсы, а также отсутствие четкого тренда их изменения в долгосрочной перспективе. Волатильность энергетического рынка, обусловленная ростом политической напряженности между странами, научно-техническим прогрессом, неоднородным развитием мировой энергетики, ростом обеспокоенности мировой общественности вопросами экологической безопасности и другими факторами, описанными в частности в монографиях, изданных под редакциями Надер Л. [21] и Хелм Д. [22], в среднесрочной перспективе будет расти и, как следствие, негативно отражаться на привлекательности инвестиций в акции энергетических компаний.

Отсутствие четкого направления развития энергетических рынков приводит к существованию разных прогнозов относительно возможного долгосрочного тренда цен на основной энергоресурс - нефть. Интервал прогнозируемых цен варьируется от 40 до 80 дол. за баррель в зависимости от того, какой сценарий развития возобновляемых источников энергии поддерживают эксперты, какие темпы развития мировой экономики и внедрения энергосберегающих технологий принимаются ими в качестве наиболее реальных. Однако принимая решение об инвестировании в акции российских энергетических компаний, следует учитывать тот факт, что по прогнозам ведущих специалистов-энергетиков, основанным на анализе существующих фундаментальных факторов развития мировой и отечественной экономики, в обозримом будущем (как минимум до 2050 г.) углеводороды (в частности, нефть и газ) останутся главными источниками потребляемой энергии, а их добыча и переработка - экономически выгодной деятельностью. Исходя из этого, ожидать падения курса акций российских энергетических компаний не приходится, а значит энергетические компании в среднесрочной перспективе могут рассчитывать на привлечение средств отечественного фондового рынка для решения стоящих перед ними текущих и стратегических задач.

\section{Список использованной литературы}

1. Макарова Г. Н. Энергетические риски России в XXI веке / Г. Н. Макарова. - Иркутск : Изд-во БГУ, 2016. - 224 с.

2. Русецкая Г. Д. Проблемы мирового рынка нефти, газа и нефтепродуктов / Г. Д. Русецкая. - Иркутск : Изд-во БГУЭП, 2015. - 67 с.

3. Aloui R. Relationship between oil, stock prices and exchange rates: A vine copula based GARCH method / R. Aloui, M. B. S. Anssa // The North American Journal of Economics and Finance. - 2016. - Vol. 37. - P. 458-471. - DOI: 10.1016/j.najef.2016.05.002.

4. Baruntk J. Gold, oil, and stocks: Dynamic correlations / J. Baruntk, E. Kočenda, L.Vбcha // International Review of Economics and Finance. - 2016. - № 42. - P. 186201. - DOI: 10.1016/j.iref.2015.08.006.

5. Scholtens B. Stocks and energy shocks: The impact of energy accidents on stock market value / B. Scholtens, A. Boersen // Energy. - 2011. - Vol. 36, № 3. - P. 1698-1702. DOI: $10.1016 /$ j.energy.2010.12.059.

6. Vo M. Oil and stock market volatility: A multivariate stochastic volatility perspective / M. Vo // Energy Economics. - 2011. - Vol. 33, iss. 5. - P. 956-965. - DOI: 10.1016/j. eneco.2011.03.005.

\section{Baikal Research Journal}


7. Crnigoj M. Financial constraints and corporate investments during the current financial and economic crisis: The credit crunch and investment decisions of Slovenian firms / M. Crnigoj, M. Verbic // Economic Systems. - 2014. - Vol. 38, iss. 4. - P. 502-517. DOI :10.1016/j.ecosys.2014.03.004.

8. Dimic N. The political risk factor in emerging, frontier, and developed stock markets / N. Dimic, V. Orlov, V. Piljak // Finance Research Letters. - 2015. — № 15. - P. 239245. - DOI:10.1016/j.frl.2015.10.007.

9. Goriaev A. Risks of investing in the Russian stock market: Lessons of the first decade / A. Goriaev, A. Zabotkin // Emerging Markets Review. - 2006. — № 7. — P. 380-397. — DOI:10.1016/j.ememar.2006.09.005.

10. Grout P. A. Stock market risk in the financial crisis / P. A. Grout, A. Zalewska // International Review of Financial Analysis. - 2016. - № 46. - P. 326-345. - DOI:10.1016/j. irfa.2015.11.012.

11. Li J. The returns and risks of investment portfolio in stock market crashes / J. Li, Ch. Long, X. Chen // Physica A. - 2015. - № 427. - P. 282-288. - DOI: 10.1016/j. physa.2015.02.018.

12. Prediction of stock markets by the evolutionary mix-game model / F. Chena [et al.] // Physica A. - 2008. - № 387. - P. 3594-3604.

13. Abramov A. Long-term portfolio investments: New insight into return and risk / A. Abramov, A. Radygin, M. Chernova // Russian Journal of Economics. - 2015. - Vol. 1, № 3. - P. 273-293. - DOI:10.1016/j.ruje.2015.12.001.

14. Minton B. A. Institutional investments in pure play stocks and implications for hedging decisions / B. A. Minton, C. Schrand // Journal of Corporate Finance. — 2016. Vol. 37. - P. 132-151. - DOI: 10.1016/j.jcorpfin.2015.12.013.

15. Wright G. Decision making and planning under low levels of predictability: enhancing the scenario method / G. Wright, P. Goodwin // International journal of forecasting. 2009. — № 25. - P. 813-825. — DOI: 10.1016/j.ijforecast.2009.05.019.

16. Кононов Ю. Д. Пути повышения обоснованности долгосрочных прогнозов развития ТЭК / Ю. Д. Кононов. - Новосибирск : Наука, 2015. - 147 с.

17. Методы и модели прогнозных исследований взаимосвязей энергетики и экономики / Ю. Д. Кононов [и др.]. - Новосибирск : Наука, 2009. - 178 с.

18. Кононов Ю. Д. Оценка рисков в предпринимательстве при анализе эффективности крупномасштабных проектов в ТЭК / Ю. Д. Кононов, В. И. Локтионов. - Иркутск : Изд-во БГУЭП, 2012. - 142 с.

19. Loktionov V. Nuclear Power and the Russian Energy Security Strategy/ V. Loktionov // Geopolitics of Energy. - 2017. - Vol. 39, № 2. - P. 2-8.

20. Кибалов Е. Б. Системный анализ ожидаемой эффективности крупномасштабных проектов / Е. Б. Кибалов, В. И. Горяченко, А. Б. Хуторецкий. - Новосибирск : Изд-во ИЭОПП СО РАН, 2008. - 162 с.

21. The energy reader / ed. L. Nader. - Chichester : Wiley-Blackwell, 2010. - 548 p.

22. The New Energy Paradigm / ed. D. Helm. - Oxford : Oxford University Press, 2007. $-518 \mathrm{p}$.

\section{References}

1. Makarova G. N. Energeticheskie riski Rossii $v$ XXI veke [Energy risks of Russia in the $21^{\text {st }}$ century]. Irkutsk, Baikal State University of Economics and Law Publ., 2016. $224 \mathrm{p}$.

2. Rusetskaya G. D. Problemy mirovogo rynka nefti, gaza i nefteproduktov [Problems of the world market of oil, gas and oil products]. Irkutsk, Baikal State University of Economics and Law Publ., 2015. 67 p.

3. Aloui R., Amssa M. B. S. Relationship between oil, stock prices and exchange rates: A vine copula based GARCH method. The North American Journal of Economics and Finance, 2016, vol. 37, pp. 458-471. DOI: 10.1016/j.najef.2016.05.002.

4. Baruntk J., Kočenda E., Vбcha L. Gold, oil, and stocks: Dynamic correlations. International Review of Economics and Finance, 2016, no. 42, pp. 186-201. DOI: 10.1016/j. iref.2015.08.006.

\section{Baikal Research Journal}


5. Scholtens B., Boersen A. Stocks and energy shocks: The impact of energy accidents on stock market value. Energy, 2011, vol. 36, no. 3, pp. 1698-1702. DOI: 10.1016/j. energy.2010.12.059.

6. Vo M. Oil and stock market volatility: A multivariate stochastic volatility perspective. Energy Economics, 2011, vol. 33, iss. 5, pp. 956-965. DOI: 10.1016/j.eneco.2011.03.005.

7. Crnigoj M., Verbic M. Financial constraints and corporate investments during the current financial and economic crisis: The credit crunch and investment decisions of Slovenian firms. Economic Systems, 2014, vol. 38, iss. 4, pp. 502-517. DOI :10.1016/j.ecosys.2014.03.004.

8. Dimic N., Orlov V., Piljak V. The political risk factor in emerging, frontier, and developed stock markets. Finance Research Letters, 2015, no. 15, pp. 239-245. DOI:10.1016/j. frl.2015.10.007.

9. Goriaev A., Zabotkin A. Risks of investing in the Russian stock market: Lessons of the first decade. Emerging Markets Review, 2006, no. 7, pp. 380-397. DOI:10.1016/j.ememar.2006.09.005.

10. Grout P. A., Zalewska A. Stock market risk in the financial crisis. International Re view of Financial Analysis, 2016, no. 46, pp. 326-345. DOI:10.1016/j.irfa.2015.11.012.

11. Li J., Long Ch., Chen X. The returns and risks of investment portfolio in stock market crashes. Physica A, 2015, no. 427, pp. 282-288. DOI: 10.1016/j.physa.2015.02.018.

12. Chena F., Goua Ch., Guoa X., Gaob J. Prediction of stock markets by the evolutionary mix-game model. Physica A, 2008, no. 387, pp. 3594-3604.

13. Abramov A., Radygin A., Chernova M. Long-term portfolio investments: New insight into return and risk. Russian Journal of Economics, 2015, vol. 1, no. 3, pp. 273-293. DOI:10.1016/j.ruje.2015.12.001.

14. Minton B. A., Schrand C. Institutional investments in pure play stocks and implications for hedging decisions. Journal of Corporate Finance, 2016, vol. 37, pp. 132-151. DOI: 10.1016/j.jcorpfin.2015.12.013.

15. Wright G., Goodwin P. Decision making and planning under low levels of predictability: enhancing the scenario method. International journal of forecasting, 2009, no. 25, pp. 813-825. DOI: $10.1016 /$ j.ijforecast.2009.05.019.

16. Kononov Yu. D. Puti povysheniya obosnovannosti dolgosrochnykh prognozov razvitiya $T E K$ [Ways of improving the validity of long-term forecasts for development of the FES]. Novosibirsk, Nauka Publ., 2015. 147 p.

17. Kononov Yu. D., Gal'perova E. V., Kononov D. Yu. Metody i modeli prognoznykh issledovanii vzaimosvyazei energetiki i ekonomiki [Methods and models of predictive studies of interrelations of energy and economy]. Novosibirsk, Nauka Publ., 2009. 178 p.

18. Kononov Yu. D., Loktionov V. I. Otsenka riskov $v$ predprinimatel'stve pri analize effektivnosti krupnomasshtabnykh proektov $v$ TEK [Risk assessment in business in analyzing effectiveness of large-scale projects of the FES]. Irkutsk, Baikal State University of Economics and Law Publ., 2012. 142 p.

19. Loktionov V. Nuclear Power and the Russian Energy Security Strategy. Geopolitics of Energy, 2017, vol. 39, no. 2, pp. 2-8.

20. Kibalov E. B., Goryachenko V. I., Khutoretskii A. B. Sistemnyi analiz ozhidaemoi effektivnosti krupnomasshtabnykh proektov [System analysis of expected efficiency of largescale projects]. Novosibirsk, Institut ekonomiki i organizatsii promyshlennogo proizvodstva SO RAN Publ., 2008. 162 p.

21. Nader L. (ed.). The energy reader. Chichester, Wiley-Blackwell, 2010. 548 p.

22. Helm D. (ed.). The New Energy Paradigm. Oxford, Oxford University Press, 2007. 518 p.

\section{Информация об авторах}

Локтионов Вадил Ильич - кандидат экономических наук, старший научный сотрудник отдела взаимосвязей энергетики и экономики, Институт систем энергетики им. Л.А. Мелентьева Сибирского отделения Российской академии наук, 664033, г. Иркутск, ул. Лермонтова, д. 130, e-mail: vadlok@mail.ru.

Локтионова Елена Александровна - кандидат экономических наук, старший преподаватель, кафедра банковского дела и ценных бумаг, Байкальский государственный университет, 664003, г. Иркутск, ул. Ленина, 11, e-mail: loktionova_ea@mail.ru.

\section{Baikal Research Journal}




\section{Authors}

Vadim I. Loktionov - PhD in Economics, Senior Researcher, Melentiev Energy Systems Institute of the Siberian Branch of the Russian Academy of Sciences, 130 Lermontov St., 664033, Irkutsk, e-mail: vadlok@mail.ru.

Elena A. Loktionova - PhD in Economics, Assistant Professor, Chair of Banking and Securities, Baikal State University, 11 Lenin St., 664003, Irkutsk; e-mail: loktionova_ea@ mail.ru.

\section{Для цитирования}

Локтионов В. И. Оценка влияния падения цен на нефть и ухудшения общеэкономического состояния страны на финансовую привлекательность инвестиций в акции энергетических компаний / В. И. Локтионов, Е. А. Локтионова // Baikal Research Journal. 2018. - T. 9, № 1. - DOI : 10.17150/2411-6262.2018.9(1).2.

\section{For Citation}

Loktionov V. I., Loktionova E. A. Assessment of Impact of the Sharp Price Drop of Crude Oil and Economic Crisis on Attractiveness of Stock Investment in Power Companies. Baikal Research Journal, 2018, vol. 9, no. 1. DOI: 10.17150/2411-6262.2018.9(1).2. (In Russian).

\section{Baikal Research Journal}

